\title{
Susceptibility to Stress Corrosion of Laser-Welded Composite Arch Wire in Acid Artificial Saliva
}

\author{
Chao Zhang and Xinhua Sun \\ Orthodontic Department, Jilin University, No. 1500 Qinghua Street, Changchun 130021, China \\ Correspondence should be addressed to Xinhua Sun; wojiushiwo0723@126.com
}

Received 21 January 2013; Revised 22 May 2013; Accepted 30 May 2013

Academic Editor: Hamdy Doweidar

Copyright (C) 2013 C. Zhang and X. Sun. This is an open access article distributed under the Creative Commons Attribution License, which permits unrestricted use, distribution, and reproduction in any medium, provided the original work is properly cited.

The corrosion resistance of laser-welded composite arch wire (CoAW) with $\mathrm{Cu}$ interlayer between NiTi shape memory alloy and stainless steel wire in artificial saliva with different acidities and loads was studied. It was found that both the solution $\mathrm{pH}$ and the stress had a significant influence on the corrosion behaviors of the CoAW samples. Decreasing the solution $\mathrm{pH}$ or increasing the loading stress caused the increase of $\mathrm{Cu}$ release and weight loss. The corroded morphology formed on the surfaces of the CoAW was the consequence under the combined effect of corrosion and stress.

\section{Introduction}

NiTi shape memory (Nitinol) alloy and stainless steel (SS) are widely and successfully used as orthodontic wires, selfexpanding cardiovascular and urological stents, and so forth [1-3]. However, Nitinol and stainless steel arch wires have been used, respectively, in orthodontic clinical treatment all along. Nitinol wire has a superelastic property after placement in orthodontic bracket slot leading to less pain feeling of patients and being less prone to root absorption, whereas its stiffness is small causing the anchorage teeth move which has a negative impact on orthodontic treatment. Though the stiffness of SS wire could provide adequate anchorage, it is difficult to be put into brackets with the addition of causing significant pain and alveolar bone latent excavation of absorption due to its small flexibility [3-5].

Composite arch wire (CoAW) is an arch wire solder connection made by Nitinol and SS wires. CoAW combines the advantages of both materials by virtue of correcting malposed teeth during the teeth alignment stage and at the same time maintaining the stability of the antitooth. The application of CoAW could not only effectively reduce the suffering of patients and simplify therapeutic operation, but it can also reduce the number of subsequent visits. However, successful application of any advanced material depends not only on its inherent properties, but also on the development of joining technology for itself or other dissimilar materials [6]. Therefore, laser welding was carried out to join Nitinol and SS wires with pure $\mathrm{Cu}$ interlayer. The joint tensile strength $(>520 \mathrm{MPa})$ and shape recovery ratio of Nitinol alloy HAZ $(>98 \%)$ could meet the requirements of clinical performance [7]. The excellent mechanical properties of the new type CoAW provide more and more possibility on orthodontic application. However, there is still no clinical evidence to indicate the potential carcinogenicity of orthodontic CoAW. Therefore, the biocompatibility of orthodontic CoAW is very important and worth further investigation.

The corrosion resistance of orthodontic wire is an important factor determining its biocompatibility [8]. Previously, there are many studies separately reported the corrosion behaviors of Nitinol and stainless steel [9-11]. Huang found that the SS wire showed higher pitting potential and wider passive range than Nitinol wire [12]. Huang found that decreasing the solution $\mathrm{pH}$ led to an increase in corrosion potential, corrosion rate, and passive current of the Nitinol wires [13]. The acidity changes can alter chemistry environment and biological processes around arch wires leading to the variation of corrosion resistance. However, studies on corrosion behavior of the new type orthodontic CoAW laser welded by Nitinol and SS wires with $\mathrm{Cu}$ interlayer are still missing. 


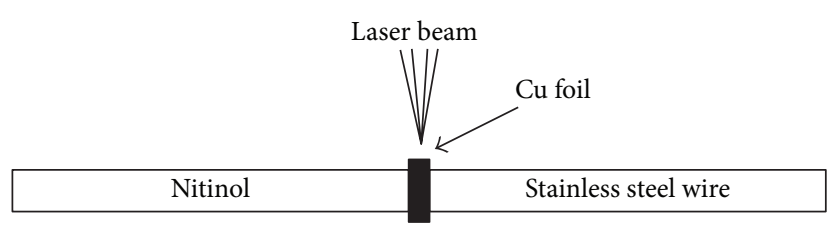

(a)

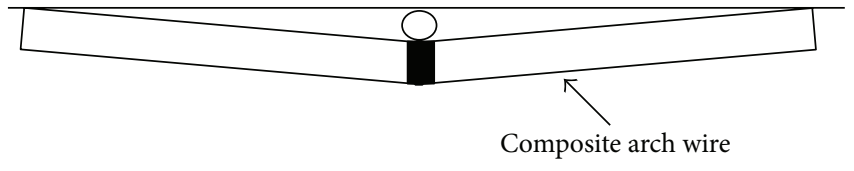

(b)

FIGURE 1: (a) Schematic diagram of laser welding; (b) device for applying 3-point bending forces to composite arch wire.

As a biomaterial like arch wire, the resistance to general and localized corrosion, as well as the resistance of harmful metal ions, is prerequisite for in-oral applications [14]. From the dental application point of view, the load plays important roles in the corrosion resistance of CoAW. Orthodontic arch wires are often working under continuous loading conditions, especially when correcting the malposed teeth. The applied forces might induce damage of the oxide film on the wire surface, and the loss of protection could allow active metal to react with the surrounding environment [15]. Wang et al. studied the stress corrosion cracking (SCC) mechanism of Nitinol wires in artificial saliva [16]. Liu et al. suggested that the passive film was not stable under loading conditions, and cracking of the passive film of Nitinol wires would occur under continuous bending stress [17]. However, studies of the corrosion behavior of CoAW which contains relatively frail copper interlayer under stress are still missing.

Therefore, in this paper, the stress corrosion behaviors of the CoAW laser welded by Nitinol and SS wires with $\mathrm{Cu}$ interlayer in artificial saliva with different acidities and loading force were studied.

\section{Experimental Details}

2.1. Materials and Samples Preparation. Ti-44.73wt. \% Ni SMA wire (purchased from Smart Co., Beijing), Fe-18Cr-8Ni stainless steel (Grikin Advanced Materials Co., Ltd.), and pure $\mathrm{Cu}$ foil were used as base metals in this investigation. The dimensions of the wires are $30 \mathrm{~mm}$ (length) $\times 0.64 \mathrm{~mm}$ (width) $\times 0.48 \mathrm{~mm}$ (thickness). The pure $\mathrm{Cu}$ interlayer is $0.2 \mathrm{~mm}$ of thickness. The base metal was ground using $\mathrm{SiC}$ papers of nos. 800, 1200, and 2000 grit to remove oxide layer and then ultrasonically degreased in acetone. The Nitinol and stainless steel wire were fixed on a self-constructed fixture by wire-to-wire butt with the pure $\mathrm{Cu}$ interlayer as shown in Figure 1(a). An Nd:YAG laser welding system (JHM-1GY 300B) with the wavelength of $1064 \mathrm{~nm}$ was used for the welding. The optimized laser parameters used in the study were $5.23 \mathrm{~J}$ (laser power), $6 \mathrm{~ms}$ (welding time), and diameter of $0.5 \mathrm{~mm}$.

\subsection{Test Solution Preparation and Stress Condition Implement.} The common physiological solution of $0.9 \% \mathrm{NaCl}$ was prepared as the chloride solution. The artificial saliva (AS) was a phosphate buffered saline solution of the composition shown in Table 1, and $\mathrm{pH}$ value was set to 6.75 and adjusted to $\mathrm{pH}$ 4.0 with lactic acid. A total of 10 groups $(2 \mathrm{pH}$ values AS and 5 loading conditions) were investigated for stress tests and each
TABLE 1: Modified Fusayama artificial saliva used in this study.

\begin{tabular}{lc}
\hline Composition & $\mathrm{mg} / \mathrm{L}$ \\
\hline $\mathrm{NaCl}$ & 400 \\
$\mathrm{KCl}$ & 400 \\
$\mathrm{CaCl} \cdot 2 \mathrm{H}_{2} \mathrm{O}$ & 795 \\
$\mathrm{NaH} \cdot \mathrm{PO}_{4} \cdot \mathrm{H}_{2} \mathrm{O}$ & 690 \\
$\mathrm{KSCN}$ & 300 \\
$\mathrm{Na}_{2} \mathrm{~S} \cdot 9 \mathrm{H}_{2} \mathrm{O}$ & 5 \\
Urea & 1000 \\
\hline
\end{tabular}

group contained 5 specimens. All the wires were mechanically grinded using $\mathrm{SiC}$ papers up to no. 2000 grit and ultrasonically cleaned in $95 \%$ alcohol and then rinsed with double-distilled water.

The specimens were immersed in modified Fusayama artificial saliva with different acidities and maintained at $37^{\circ} \mathrm{C}$ for periods up to 28 days. A 3-point flexure fixture, made of ceramic sheet, was used to apply a continuous bending force that deflected the displacement of $1.0,2.0,3.0,5.0 \mathrm{~mm}$ as shown in Figure 1(b). The wires were fixed in the solution with a free length of $60 \mathrm{~mm}$. The unbent specimens were also placed in the same designed vessel without applied force.

After 14 days of immersion, the solution was collected and substituted by the new solution, and after 28 days each retrieved sample was cleaned. Precision electronic balance (M2-P, Sartorius, Germany) was used to measure the weight changes after soaking in artificial saliva. The collected solutions were individually analyzed for copper using an inductively coupled plasma-optical emission spectrometer (ICP-OES, Optima 3300DV, Perkin Elmer, Boston, USA). The detection limit of ICP-OES used in this study was $0.01 \mathrm{ppm}$ for copper ion.

2.3. Electrochemical Measurements. All the electrochemical measurements were performed using a CHI 920C electrochemical workstation. The counter electrode was a rectangular platinum plate and the reference electrode was a saturated calomel electrode (SCE). Additionally, the test solutions were not deaerated before the electrochemical measurement. All test samples were mechanically ground using $\mathrm{SiC}$ papers up to no. 2000 grit to guarantee consistent surface roughness and then embedded in cold-curing epoxy resin, exposing a sample surface area of $20 \times 0.64 \mathrm{~mm}^{2}$.

After an initial delay of $60 \mathrm{~min}$ to accomplish the equilibrium, the scanning rate was $5 \mathrm{mV} / \mathrm{s}$, starting from-1 V/SCE to remove the surface film heterogeneity. The cyclic 


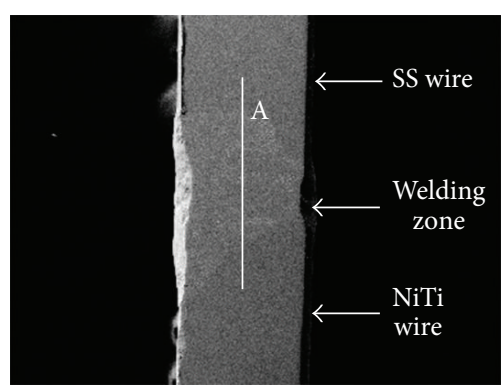

(a)

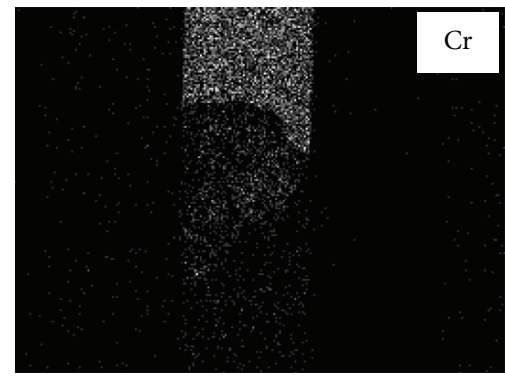

(d)

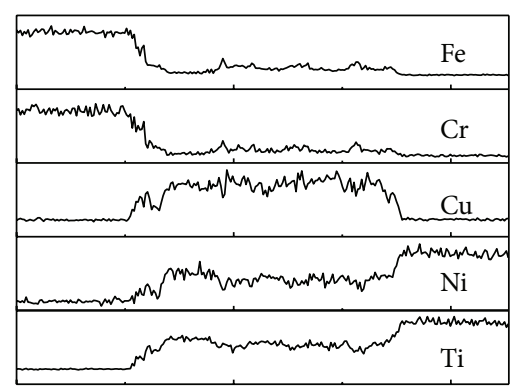

(b)

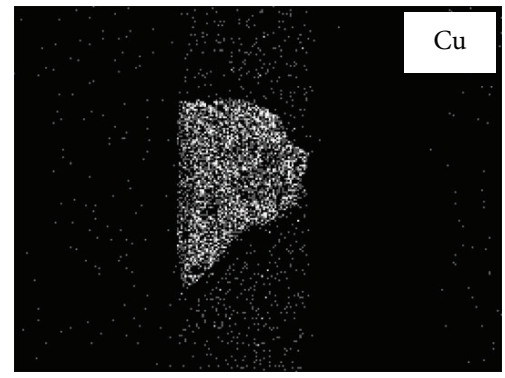

(e)

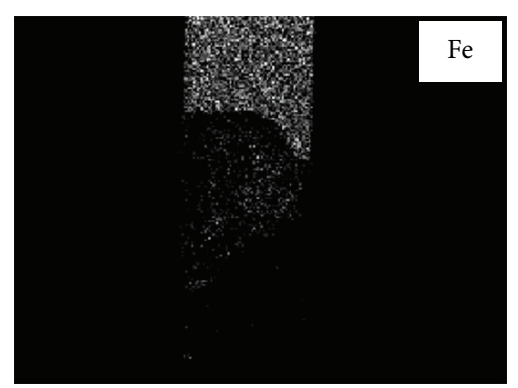

(c)

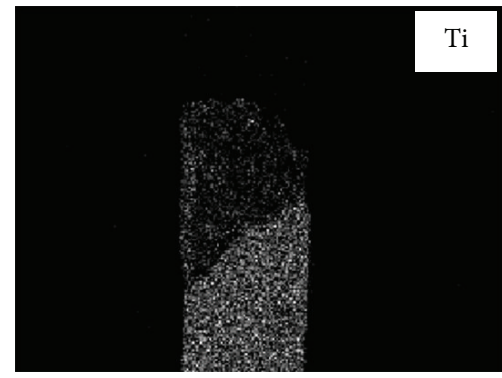

(f)

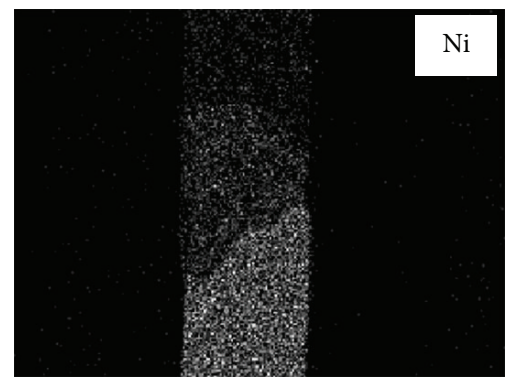

(g)

FIGURE 2: (a) SEM surface morphologies of the welded composite arch wire; (b) EDS line analysis of the welded composite arch wire; ((c)-(g)) map EDS analysis of the welded composite arch wire.

potentiodynamic tests were conducted between -1000 and $+1500 \mathrm{mV}$. Each test contained 3 specimens.

2.4. SEM Surface Morphology. The surface morphologies of composite orthodontic wires were observed using environmental scanning-electron microscopy (SEM, ZEISS EVO18, Germany) equipped with an energy dispersive spectrometer (EDS) analyzer (INCA-X-Max, UK).

\section{Results and Discussion}

3.1. Microstructure of the CoAW. Figure 2 shows surface morphologies of the welding zone between the dissimilar materials. It can be seen that the surface of the welding zone was smooth and complete, free of any apparent pores or other defects. According to the map EDS analysis, the welding zone shows a heterogeneous composition. From stainless steel to Nitinol side, the concentrations of Fe and $\mathrm{Cr}$ decrease and the concentrations of $\mathrm{Ti}$ and $\mathrm{Ni}$ have an increased tendency. Furthermore, $\mathrm{Cu}$ element distributes homogeneously in the welding zone, Figures 2(b)-2(g).
3.2. Potentiodynamic Polarization Measurement. The effects of chloride and $\mathrm{pH}$ on potentiodynamic polarization behaviors of CoAW are shown in Figure 3, and the detailed electrochemical parameters are listed in Table 2 . It can be seen that the cathodic section of the polarization curves comprised two distinct stages. For the anodic polarization curves, the CoAW exhibited a typical passive region up to the pitting potential in the $\mathrm{pH}=6.75$ AS solution compared the other two solutions. The passive region of the chloride solution polarization curves was much smaller than the section of artificial saliva polarization curves. The corrosion potentials remained very similar as $\mathrm{pH}$ increased, whereas the pitting potential $\left(E_{\text {pit }}\right)$ as well as passive current densities of $\mathrm{pH}=6.75$ was higher than that in $\mathrm{pH}=4.0$ solution.

3.3. Cyclic Potentiodynamic Polarization Measurement. In order to evaluate the repassivation ability of CoAW in the three categories of solutions, cyclic potentiodynamic polarization measurements were carried out. Figure 4 presents typical cyclic polarization curves of CoAWs in $\mathrm{PH}=6.75$, 4.0 artificial saliva, and $0.9 \% \mathrm{NaCl}$ solution. In all the three 


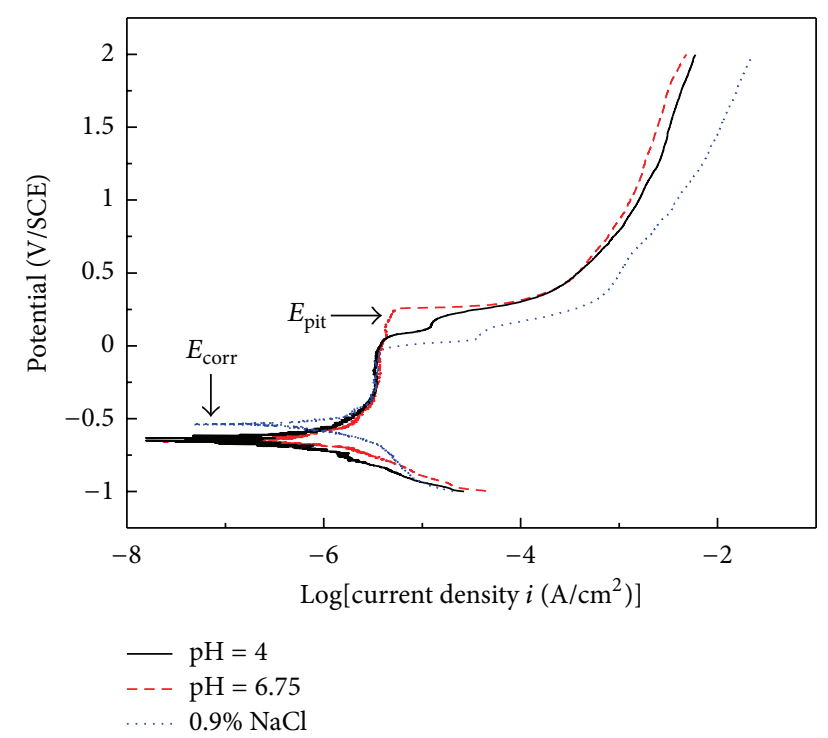

FIgURE 3: Polarization curves for composite arch wires in different solutions.

solutions, no obviously hysteresis loop occurred in the reverse anodic scan. The reprotection potentials $\left(E_{\text {prot }}\right)$ were much higher than the free corrosion potentials $\left(E_{\text {corr }}\right)$. Moreover, the reprotection potential of the CoAW in the $0.9 \% \mathrm{NaCl}$ solution is a little lower than in the acid AS solutions.

The SEM images of the CoAWs after the cyclic potentiodynamic polarization measurement are shown in Figure 5. It can be seen that the CoAWs in the $0.9 \% \mathrm{NaCl}$ solution were easily corroded compared to these in the artificial saliva solutions.

3.4. Corrosion Tests with Applied Stress. After soaking in AS at both $\mathrm{pH} 4.0$ and 6.75 with different stresses, the typical surface morphologies of CoAWs are shown in Figure 6. Copper element release and weight loss are shown in Figure 7. It can be seen that under both unstressed and stressed circumstances, no obvious degradation occurred after 28 days of immersion in artificial saliva, regardless of the $\mathrm{pH}$ value. Furthermore, the interlayer part of stressed wires showed more irregular surfaces than unstressed wires. With the increase of applied loading force, the corrosive surface performed rougher. The $\mathrm{Cu}$ release and weight loss increase with the decrease in $\mathrm{pH}$ and increase in applied loading force.

3.5. Discussion. The biocompatibility of orthodontic arch wire is thought to depend mainly on the host reaction induced by the degradation of the material in bodily environment. The biologic response to metal is directly related to its corrosion performance, which is associated with the protective oxide film on the surface [15]. CoAWs are subject to mechanical stresses and deformation for tooth movement, which might induce damage of the oxide film on the wire surface and allow active metal to react with the surrounding environment. Therefore, in this study, we investigated the

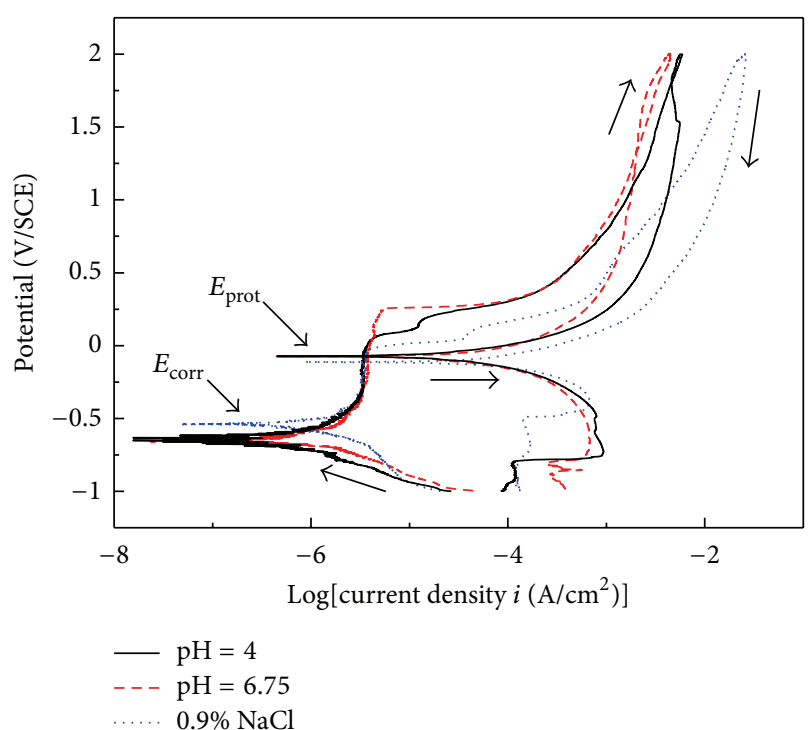

FIGURE 4: Representative cyclic polarization curves of composite arch wires in different solutions.

effect of bending stress and $\mathrm{pH}$ values on corrosion performance of CoAW in vitro.

As indicated, different environments have important effect on the corrosion performance of CoAW. The standard and cyclic potentiodynamic tests were used to estimate the corrosion behaviors in different solutions. The results of standard potentiodynamic polarization test are shown in Figure 3 and Table 2 . The pitting potential $\left(E_{\text {pit }}\right)$ is used to evaluate the corrosion resistance. $E_{\text {pit }}$ represents conservative measures of anodic pitting tendency because it shows minimum potential below which pitting cannot be sustained [18]. The nearly vertical stage at lower potential corresponds to the hydrogen generation process, whereas the sloped region represents the oxygen consumption process. The $E_{\text {pit }}$ of two acidities artificial saliva solution was higher than that of $\mathrm{NaCl}$ solution, which may be due to the inhibitory effect of other ions in artificial saliva [19]. The explanation of this phenomenon is based on research showing that natural calcium phosphate layers will naturally form in complex simulated physiological solutions due to certain inhibiting ions, such as $\mathrm{CaCl}_{2}$ and phosphate which would possibly act as further protective barriers against the corrosion process [20]. Although the pitting potential $\left(E_{\text {pit }}\right)$ in $\mathrm{pH}=6.75$ was extended to higher potential value compared with $\mathrm{pH}=4.0$, the pitting potentials in both solutions were large. Therefore, the pitting corrosion is not easy to occur. Decreasing the $\mathrm{pH}$ value leading to a decrease in the $E_{\text {pit }}$ and passive range for composite arch wire indicated that the pitting corrosion resistance and passivity breakdown resistance of CoAW were more susceptible to the $\mathrm{pH}$ variation. With the increase in potential, the movement of ions was controlled by the electronic potential rather than by diffusion, where CoAW exhibited increase in current density at the same point of pitting potential, indicating the abrupt damage of the protective film was compatible with a passivity 


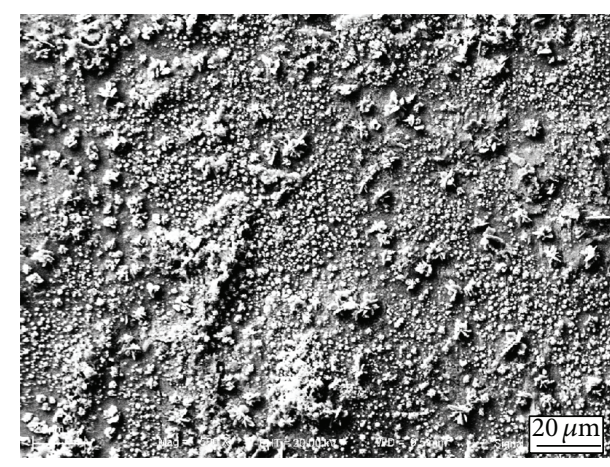

(a)

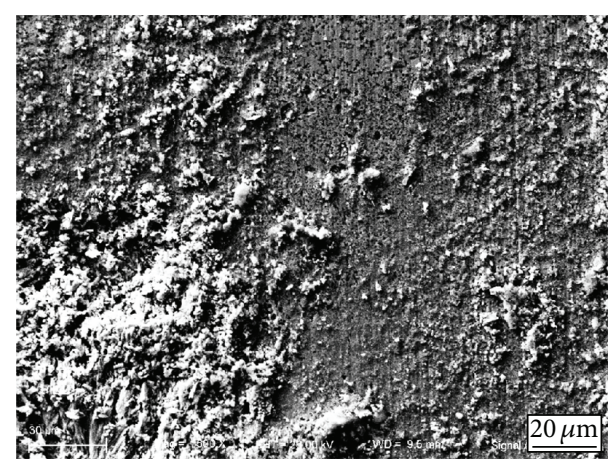

(b)

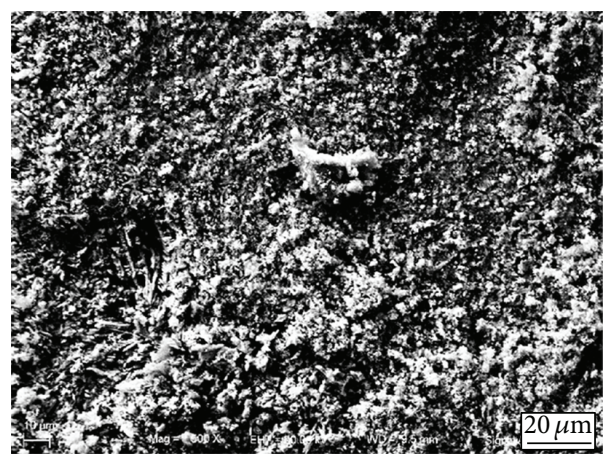

(c)

FIGURE 5: SEM surface morphologies of potentiodynamic polarized composite arch wires: (a) pH 4.0; (b) $\mathrm{pH} 6.75$; (c) $0.9 \% \mathrm{NaCl}$.

TABLE 2: The pitting potential $\left(E_{\text {pit }}\right)$, corrosion potential $\left(E_{\text {corr }}\right)$ with respect to SCE, and corrosion current density $\left(I_{\text {corr }}\right)$ extracted from potentiodynamic polarization curve.

\begin{tabular}{lccc}
\hline Solution type & $E_{\text {pit }}(\mathrm{V})$ & $E_{\text {corr }}(\mathrm{V})$ & $I_{\text {corr }}\left(\mu \mathrm{A} / \mathrm{cm}^{2}\right)$ \\
\hline $\mathrm{pH}=4.0$ & $0.121(0.010)$ & $-0.628(0.011)$ & $1.38(0.014)$ \\
$\mathrm{pH}=6.75$ & $0.260(0.012)$ & $-0.641(0.014)$ & $1.02(0.006)$ \\
$\mathrm{NaCl}$ & $0.052(0.008)$ & $-0.534(0.016)$ & $1.58(0.011)$ \\
\hline
\end{tabular}

regime occurring before the breakdown potential. Additionally, the corrosion current densities and passivation current densities in the three solutions are similar, which means that the value of corrosion current density attacking the entire material rapidly is the same [21].

In Figure 4, there was a smaller hysteresis loop in the polarization curve, which suggested that the CoAW did not experience true localized corrosion in the experimental solutions. Although it appears that there was an initial small degree of pitting, this did not develop into large pitting because the surrounding corrosion quickly eliminated it. The reverse of the anodic potential in cyclic potentindynamic test was scanned down to interact with the passive region. The interaction at the passive region defined protection potential $\left(E_{\text {prot }}\right)$. Wilde reported that the difference between $E_{\text {pit }}$ and $E_{\text {prot }}$ can be correlated with the resistance to crevice corrosion. The higher difference between $E_{\text {pit }}$ and $E_{\text {prot }}$ means the higher susceptibility of an alloy to crevice corrosion [22]. In our study, the difference between $E_{\text {pit }}$ and $E_{\text {prot }}$ is small which means lower susceptibility to crevice corrosion. Therefore, regardless of the solution type, the transpassive region in the polarization curves for composite wires was a result of uniform corrosion. On the other hand, the $E_{\text {prot }}$ above the corresponding $E_{\text {corr }}$ indicates that the specimens are capable of repassivation when the passive film is damaged [23]. Transpassivation takes place with the generation of oxygen gas accompanied by the anodic dissolution of a metallic ion, which was copper ion in this study. The corrosion resistance of copper in the interlayer is mainly dependent on the oxidation product formed on the surface after the initial corrosion. The copper corrosion kinetics, with the increased coverage of the surface of the corrosion product, is mainly decided by the surface concentration of adsorbed oxygen. Generally, the corrosion process of $\mathrm{Cu}$ causes the increase of $\mathrm{pH}$ value of solution, which would reduce the corrosion rate. As a result, the corrosion performance of CoAW in $\mathrm{pH}=$ 4.0 artificial saliva is almost the same as the neutral saliva in electrochemical and SEM results. However, more severely damaged surface and spongy morphology were observed on tested interlayer surfaces of composite wire in chloric solution. The reason was stated in the proceeding part and supported by the study of Kim and Johnson which showed that Nitinol wire revealed extensive pitting and localized corrosion after potentiodynamic polarization tests in $0.9 \%$ $\mathrm{NaCl}$ solution [24].

Another important aspect of the biocompatibility behavior of CoAWs is their corrosion performance under stress condition in applications. Bending stress used in this study, 


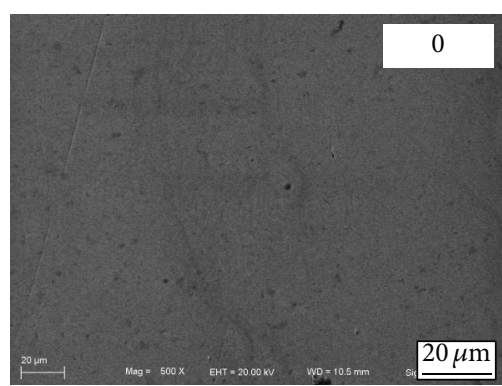

(a)

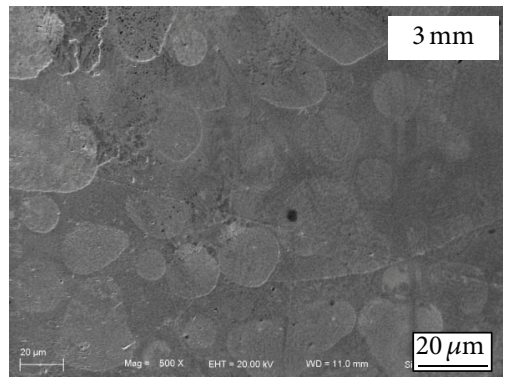

(d)

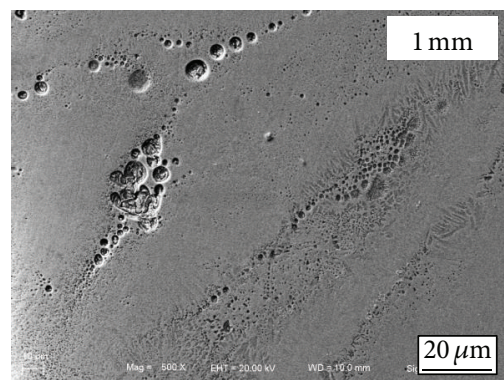

(g)

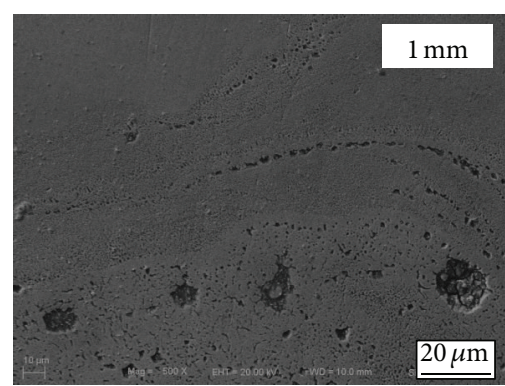

(b)

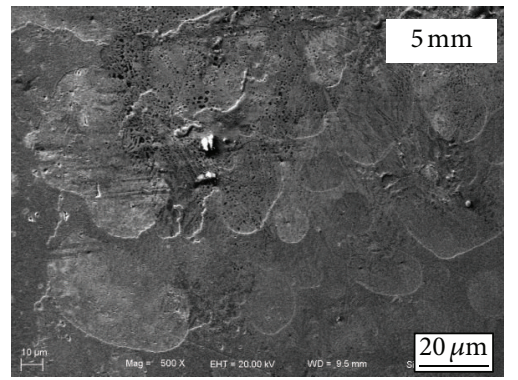

(e)

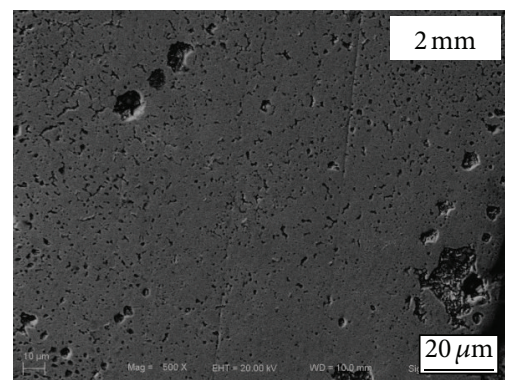

(h)

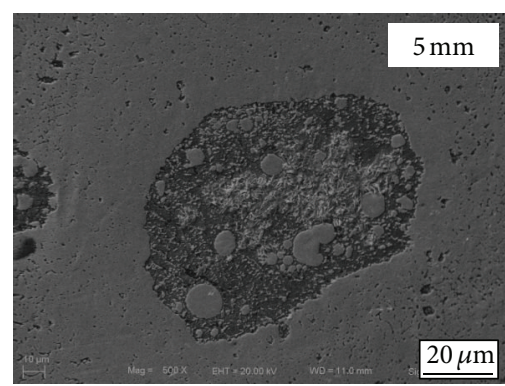

(j)

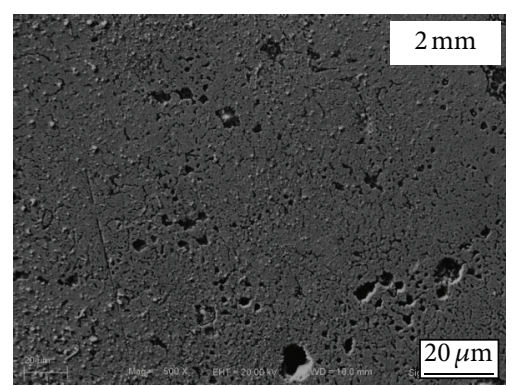

(c)

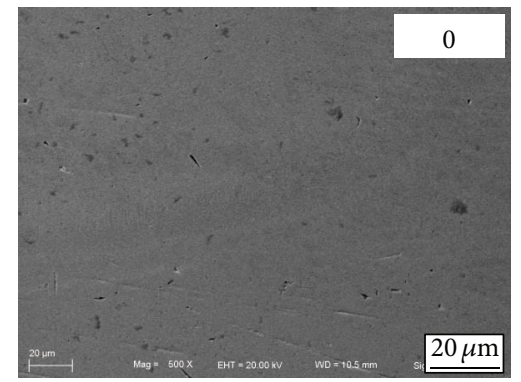

(f)

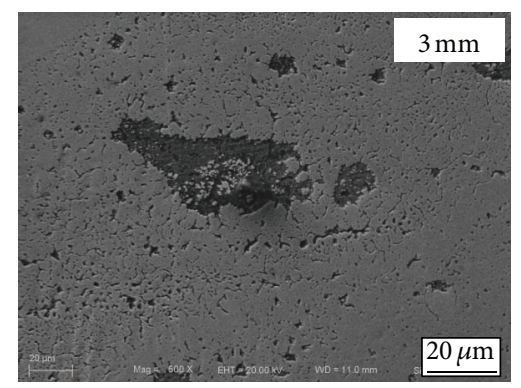

(i)

FIGURE 6: SEM surface morphologies of unstressed and stressed composite arch wires immersed in artificial saliva with different $\mathrm{pH}$ : ((a)-(e)) $\mathrm{pH}=4.0 ;((\mathrm{f})-(\mathrm{j})) \mathrm{pH}=6.75$.

unlike tensile stress, could cause homogenous deformation of orthodontic wires which would start at an initial point and propagate along the wires then allow body fluids and tissues to touch the wire surface under the damaged oxide layer. Rondelli and Vicentini found no effect of $4 \%$ strain on the localized corrosion behavior of Nitinol wires [25]. Huang mentioned that the applied tensile stress would not change the corrosion resistance of as-received Nitinol wires in artificial saliva at both $\mathrm{pH}$ values 2 and 5 [12]. It was suggested that the passive film of specimens would be damaged under bending condition more than under tensile stress. In this study we simulate the real corrosion conditions to evaluate the corrosion behavior of CoAW in orthodontic applications. An electrolytic cell is formed between the stressed and unstressed metal portions and grain boundaries of stressed metal are most vulnerable to corrosion. The failure of the soldered joint or the flaking away of a thin margin of metal would occur due to stress corrosion [26]. As previously discussed, 


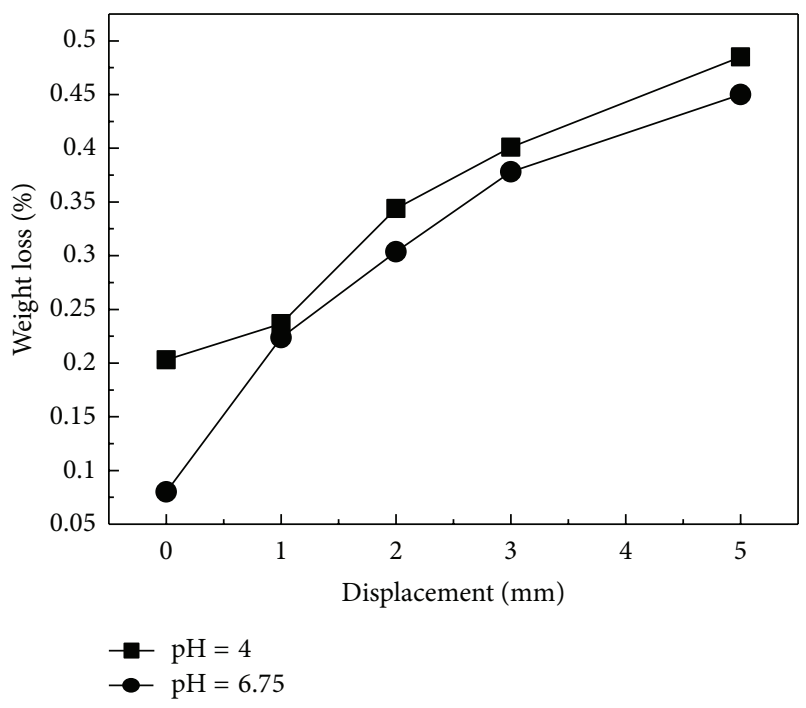

(a)

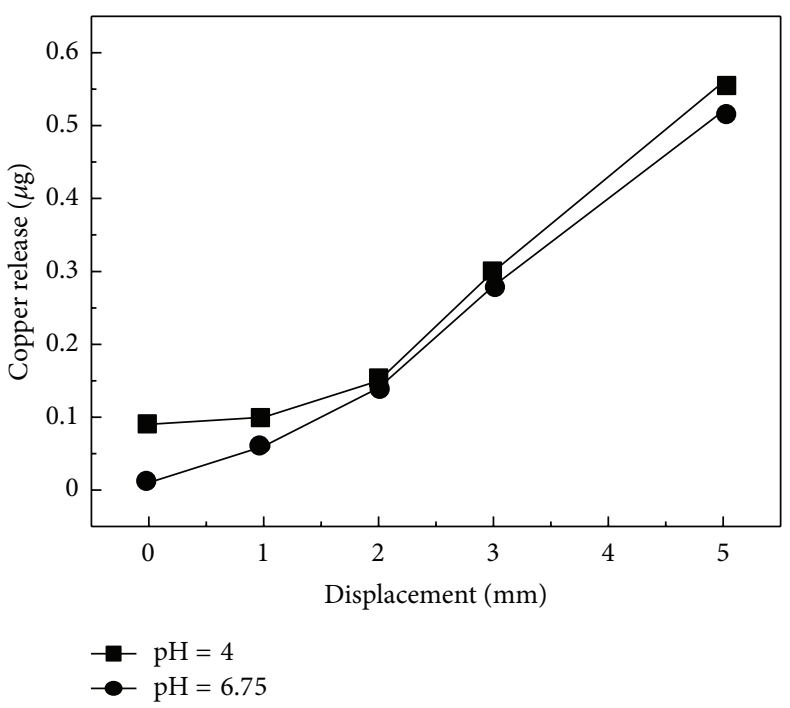

(b)

FIGURE 7: (a) Weight loss and (b) copper release of the composite arch wires in artificial saliva with different pH values.

the acid solution is easier to react with the CoAW than the neutral solution. The $\mathrm{Cu}$ release and weight loss in the $\mathrm{pH}$ $=4.0$ solution is larger than that in the $\mathrm{pH}=6.75$ solution. On the other hand, for the static corrosion test in which the force displacement is 0 , the $\mathrm{Cu}$ release and weight loss is low. The reason is that the surface is protected by the oxide layer. For the stress corrosion, the 3 -point bending method would induce buckling or cracking of the oxide layer of interlayer part, and loss of this protection allows the active metal to react with surrounding environment. With the increase of the applied loading force, more $\mathrm{Cu}$ release and larger weight loss occurred in both $\mathrm{pH}=4.0$ and 6.75 artificial saliva solutions. The utmost weight losses and copper element release of CoAW were under the condition of $\mathrm{pH}=4.0$ and force displacement $5 \mathrm{~mm}$. The results come to an agreement with conclusion of Liu et al. that the stressed Nitinol wires exhibited substantial increase in nickel release compared with the unbent specimens at different $\mathrm{pH}$ values AS [17].

As shown in Figure 6, both stressed and unstressed specimens showed uniform corrosion but relative intact surface in longer period of artificial saliva immersion. Under the same applied force, the CoAW is more corrodible to the acid artificial saliva. With the increase of the applied loading force, the surface of the CoAW becomes rougher due to the break of the oxide film under the bending force.

For clinical applications, the orthodontic arch wires have dynamic conditions rather than static conditions, which possibly damage the passive film. The open metal surface would react with the aggressive solution and release metal ions into the surrounding environment. We must understand the stress on corrosion behavior and ion release to ensure the stable surface properties of CoAW in clinical use and reexamine the loading conditions with respect to corrosion behavior. In clinical applications, orthodontic wires would be used for more than 1 month, and the continuous bending stress and acidity variation would affect the properties of the passive film of the composite wires. Therefore, the factor of stress and acidity should be considered on the corrosion behavior in the design and clinical use of CoAW and related-alloy wires. The clinical application and performance improvements of CoAW must refer to the results of $\mathrm{pH}$ and stress corrosion.

\section{Conclusions}

Under the different experimental conditions of this study, the following conclusions were drawn.

(1) Through the polarization test, the CoAW seems easily occurred with uniform corrosion in the artificial saliva solution. With the decrease of the $\mathrm{pH}$, the corrosion resistance becomes worse.

(2) The applied bending stress would break the oxide film on the surface of the CoAW which leads to more $\mathrm{Cu}$ release and larger weight loss. The most serious corrosion occurred under the largest stress and lowest $\mathrm{pH}$ value.

(3) The factor of stress and acidity must be considered on the corrosion behavior in the design and clinical use of CoAW and related-alloy wires.

\section{References}

[1] C. W. Chan, H. C. Man, and T. M. Yue, "Effect of post-weld heattreatment on the oxide film and corrosion behaviour of laserwelded shape memory NiTi wires," Corrosion Science, vol. 56, pp. 158-167, 2012.

[2] N. B. Morgan, "Medical shape memory alloy applications-the market and its products," Materials Science and Engineering A, vol. 378, no. 1-2, pp. 16-23, 2004.

[3] W. A. Brantley, Orthodontic Materials: Scientific and Clinical Aspects, Thieme, New York, NY, USA, 2001. 
[4] R. P. Kusy, "A review of contemporary archwires: their properties and characteristics," Angle Orthodontist, vol. 67, no. 3, pp. 197-207, 1997.

[5] S. A. Thompson, "An overview of nickel-titanium alloys used in dentistry," International Endodontic Journal, vol. 33, no. 4, pp. 297-310, 2000.

[6] N. J. Noolu, H. W. Kerr, Y. Zhou, and J. Xie, "Laser weldability of Pt and Ti alloys," Materials Science and Engineering A, vol. 397, no. 1-2, pp. 8-15, 2005.

[7] D. Q. Sun and H. M. Li, "A new method of TINi shape memory alloy and austenitic stainless steel different Kind of material connection," CN Patent, CNIO2152017, 2011.

[8] N. Schiff, B. Grosgogeat, M. Lissac, and F. Dalard, "Influence of fluoridated mouthwashes on corrosion resistance of orthodontics wires," Biomaterials, vol. 25, no. 19, pp. 4535-4542, 2004.

[9] G. Rondelli, "Corrosion resistance tests on NiTi shape memory alloy," Biomaterials, vol. 17, no. 20, pp. 2003-2008, 1996.

[10] Y. Okazaki and E. Gotoh, "Metal release from stainless steel, CoCr-Mo-Ni-Fe and Ni-Ti alloys in vascular implants," Corrosion Science, vol. 50, no. 12, pp. 3429-3438, 2008.

[11] C. Liu, P. K. Chu, G. Lin, and D. Yang, "Effects of Ti/TiN multilayer on corrosion resistance of nickel-titanium orthodontic brackets in artificial saliva," Corrosion Science, vol. 49, no. 10, pp. 3783-3796, 2007.

[12] H.-H. Huang, "Corrosion resistance of stressed NiTi and stainless steel orthodontic wires in acid artificial saliva," Journal of Biomedical Materials Research A, vol. 66, no. 4, pp. 829-839, 2003.

[13] H.-H. Huang, "Surface characterizations and corrosion resistance of nickel-titanium orthodontic archwires in artificial saliva of various degrees of acidity," Journal of Biomedical Materials Research A, vol. 74, no. 4, pp. 629-639, 2005.

[14] J. C. Wataha, "Biocompatibility of dental casting alloys: a review," Journal of Prosthetic Dentistry, vol. 83, no. 2, pp. 223234, 2000.

[15] J. C. Setcos, A. Babaei-Mahani, L. D. Silvio, I. A. Mjör, and N. H. F. Wilson, "The safety of nickel containing dental alloys," Dental Materials, vol. 22, no. 12, pp. 1163-1168, 2006.

[16] J. Wang, N. Li, G. Rao, E.-H. Han, and W. Ke, "Stress corrosion cracking of NiTi in artificial saliva," Dental Materials, vol. 23, no. 2, pp. 133-137, 2007.

[17] J.-K. Liu, T.-M. Lee, and I.-H. Liu, "Effect of loading force on the dissolution behavior and surface properties of nickel-titanium orthodontic archwires in artificial saliva," The American Journal of Orthodontics and Dentofacial Orthopedics, vol. 140, no. 2, pp. 166-176, 2011.

[18] M. D. Ralph, T. D. Bold, and M. J. Johnson, Corrosion of Stainless Steel, Materials Park, Ohio, OH, USA, 1987.

[19] K. Y. Chiu, F. T. Cheng, and H. C. Man, "Corrosion behavior of AISI 316L stainless steel surface-modified with NiTi," Surface and Coatings Technology, vol. 200, no. 20-21, pp. 6054-6061, 2006.

[20] D. J. Wever, A. G. Veldhuizen, J. de Vries, H. J. Busscher, D. R. A. Uges, and J. R. van Horn, "Electrochemical and surface characterization of a nickel-titanium alloy," Biomaterials, vol. 19, no. 7-9, pp. 761-769, 1998.

[21] K.-T. Oh, C.-J. Hwang, Y.-S. Park, and K.-N. Kim, "In vitro corrosion resistance of orthodontic super stainless steel wire. The effects of stress relieving heat-treatment," Journal of the Electrochemical Society, vol. 149, no. 9, pp. B414-B421, 2002.
[22] B. E. Wilde, "A critical appraisal of some popular laboratory electron chemical tests for predicting the localized corrosion resistance of stainless alloys in seawater," Corrosion, vol. 28, no. 8, pp. 283-291, 1972.

[23] A. Anderko, N. Sridhar, and D. S. Dunn, "A general model for the repassivation potential as a function of multiple aqueous solution species," Corrosion Science, vol. 46, no. 7, pp. 1583-1612, 2004.

[24] H. Kim and J. W. Johnson, "Corrosion of stainless steel, nickeltitanium, coated nickel-titanium, and titanium orthodontic wires," Angle Orthodontist, vol. 69, no. 1, pp. 39-44, 1999.

[25] G. Rondelli and B. Vicentini, "Evaluation by electrochemical tests of the passive film stability of equiatomic Ni-Ti alloy also in presence of stress-induced martensite," Journal of Biomedical Materials Research, vol. 51, no. 1, pp. 47-54, 2000.

[26] D. Upadhyay, M. A. Panchal, R. S. Dubey, and V. K. Srivastava, "Corrosion of alloys used in dentistry: a review," Materials Science and Engineering A, vol. 432, no. 1-2, pp. 1-11, 2006. 

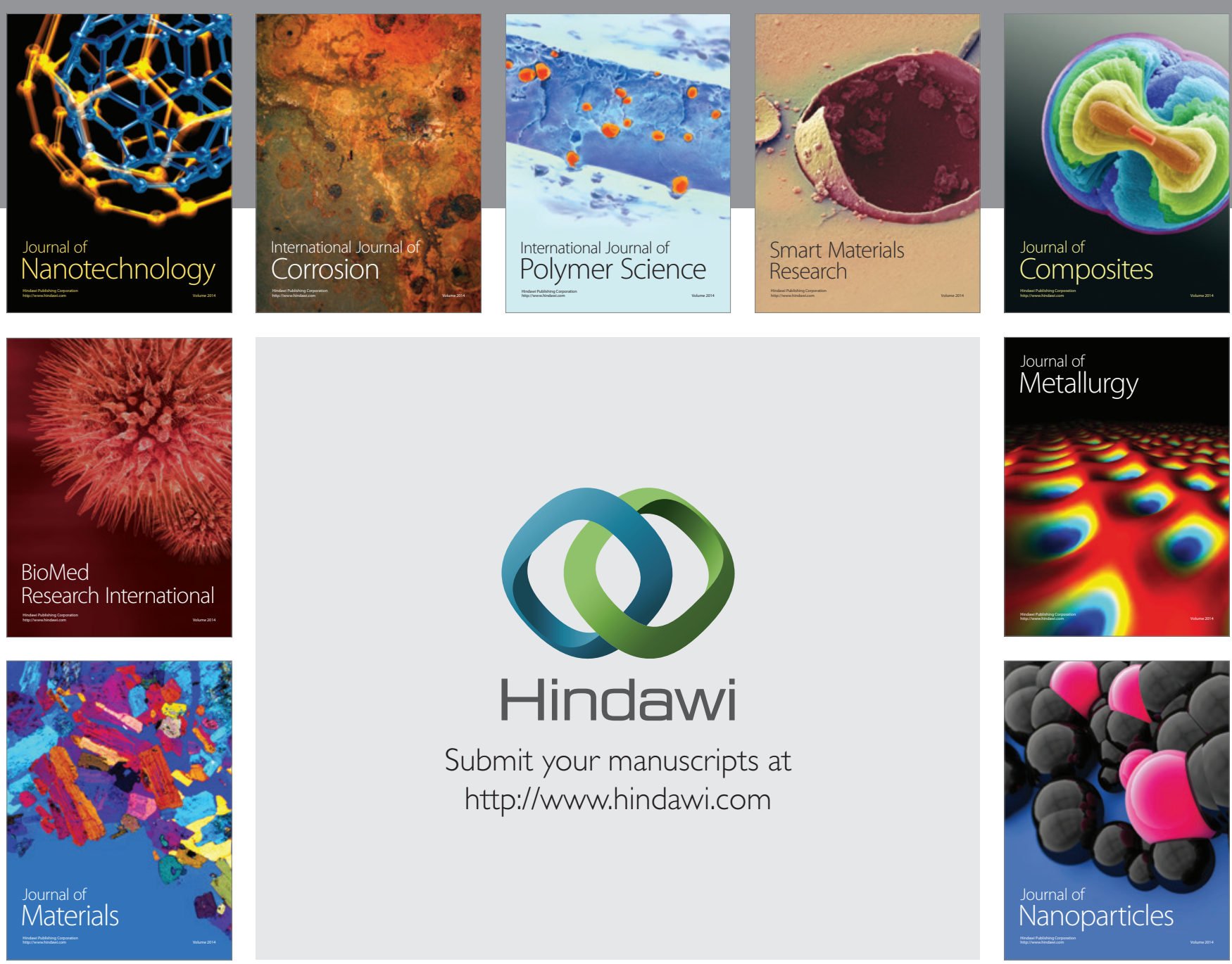

Submit your manuscripts at http://www.hindawi.com
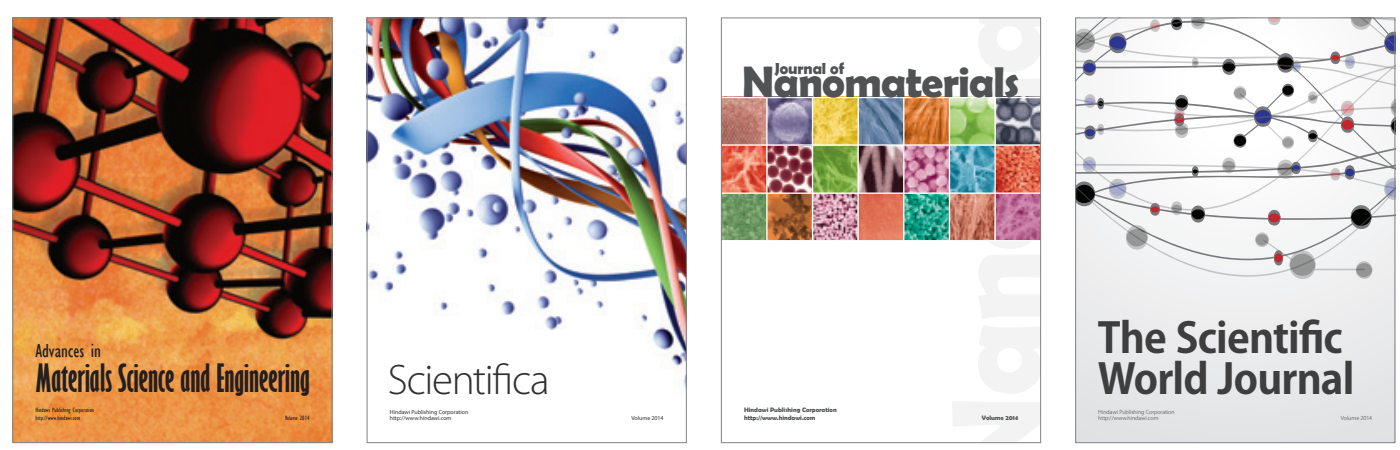

\section{The Scientific World Journal}
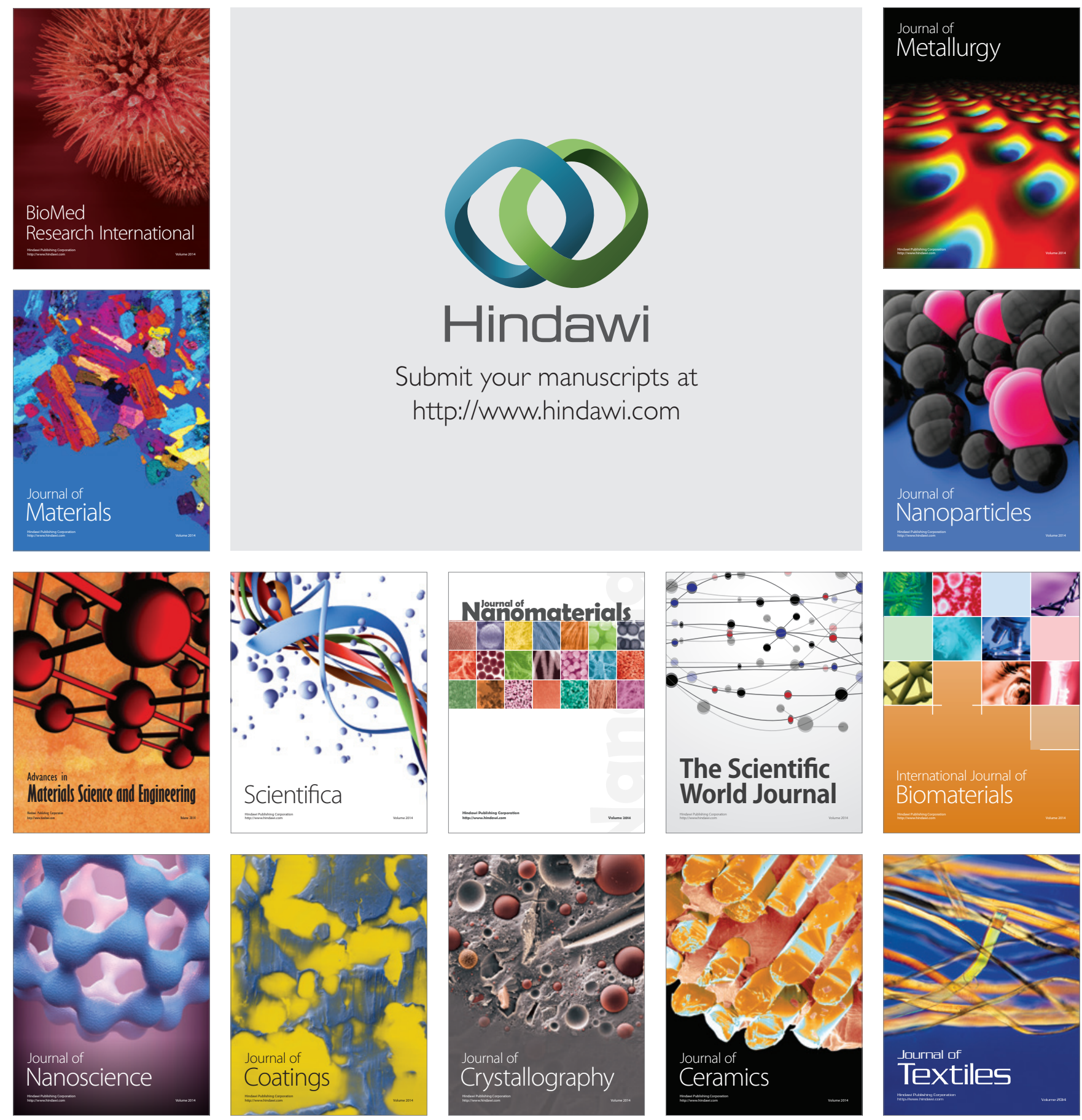